\title{
THE EFFECT OF SEPTAL LESION ON NALOXONE INDUCED HYPOPHAGIA IN RATS
}

A.R. Gargate ${ }^{1}$, R.V. Gargate ${ }^{2}$

\section{HOW TO CITE THIS ARTICLE:}

A.R. Gargate, R.V. Gargate. "The Effect of Septal Lesion on Naloxone Induced Hypophagia in Rats". Journal of Evolution of Medical and Dental Sciences 2014; Vol. 3, Issue 07, February 17; Page: 1625-1632,

DOI: $10.14260 /$ jemds/2014/2035

\begin{abstract}
AIM: Ventromedial hypothalamus and lateral hypothalamus are well known for their role in regulation of food intake. Septum is key component of limbic system which has reciprocal connections with lateral hypothalamus. These septal projections to lateral hypothalamus are thought to affect food intake. Opioid system is one of the systems affecting food intake. Agonists of Opioid receptors increase food intake while antagonists of these receptors decrease food intake. Also there is considerable amount of opioid receptors in septal nuclei and around area. Opioid antagonist naloxone is known to have hypophagic property, its mechanism of action being competitive blockade of opioid receptors in CNS. So the aim of the study was to find out the effect of septal lesion on naloxone induced hypophagia in Wistar rats. METHODS: After measuring the baseline food intake in 20 healthy adult male rats and 20 healthy adult female rats in the deprivation paradigm, the effect of naloxone on fasting animals was measured. Male and female rats were then subjected to septal lesions. After 10 days of operative recovery, the basal food intake and effect of naloxone injection on food intake after $24 \mathrm{hrs}$. of fasting was measured again. These observations were compared to those before the lesion. RESULTS: 1) It was confirmed that naloxone induces hypophagia in food deprived male and female rats. 2) Hypophagia was seen in initial hours in deprivation paradigms. 3) In rats there was no significant change in food intake after septal lesion. However, 4) after septal lesion, naloxone failed to induce hypophagia. CONCLUSION: 1) Naloxone induces hypophagia in deprived male and female rats. 2) Septal lesions do not alter food intake but they abolish hypophagic effect of naloxone in rats.
\end{abstract}

KEYWORDS: Food intake, hypophagia, naloxone, septal lesion.

INTRODUCTION: Currently, obesity is a global health problem. ${ }^{1}$ Obesity occurs due to increased consumption of energy dense diet combined with decline in energy expenditure that is associated with sedentary lifestyle. Control of weight gain is modulated by diverse neurochemical and neuroendocrine signals from different organs in the body and diverse regions in the brain. Hypothalamus plays an integrative function in this process acting through variety of systems. Hetherington and Ranson demonstrated in that lesions of ventromedial hypothalamus (VMH) produced hyperphagia and obesity. ${ }^{2}$ On the other hand Anand and Brobeck in 1951 showed that destruction of lateral hypothalamus (LH) caused hypophagia ${ }^{3,4}$. This indicates that hypothalamus and its inputs and outputs are involved in control of feeding. The septal area (septal nuclei) receives input from LH and projects monosynaptically to the LH. So LH might thus be expected to provide contextual information to the hypothalamus ${ }^{5}$. Swanson and Cowen have demonstrated that various part of septal nuclei project substantially to $\mathrm{LH}^{6}$. It is through these connections to LH the septal nuclei may influence food intake. So lesion in this area is expected to affect food intake. 
Different sets of substances in hypothalamus also appear to control food intake. One of them is opioid peptides7,8. In recent years, a considerable amount of experimental data has been accumulated which indicates that the endogenous opioids may play a crucial role in the regulation of appetite 9 , 10. The evidence suggests that there is considerable population of opioid receptors in the septal area. Peripherally administered opioid antagonist like naloxone may block opioid receptors in the septal nuclei and affect food intake.

Therefore the present study was conducted to find out if lesion of septum decreases food intake and also to find out if this lesion alters hypophagia induced by opioid antagonist naloxone which may normally act through septal opioid receptors along with through the opioid receptors in other areas of CNS.

MATERIALS AND METHODS: The present study was designed to explore the role of opiate receptors in septum in regulation of food intake. Approval of Institutional ethical committee was taken for the study.

Subjects: 20 healthy adult male and 20 healthy adult female Wistar rats were used for the study. The average age was 120-150 days. Animals were weighed, marked and housed in separate polyvinyl cages in animal room having maintained room temp $\left(25 \pm 2^{\circ} \mathrm{C}\right)$. They were maintained on $12 \mathrm{hrs}$. dark and $12 \mathrm{hrs}$. light cycle with standard laboratory diet and water ad lib.

First 8 days baseline food intake in all animals was recorded.

Deprivation paradigm: Then the animals were kept fasting for $24 \mathrm{hrs}$. At $9.30 \mathrm{am}$ on previous day the food was withdrawn. On the next day at 9.30am the food was weighed and introduced in cage. Then food intake was measured at $1 \mathrm{hr}, 2 \mathrm{hrs}, 3 \mathrm{hrs}$ and $24 \mathrm{hrs}$ after introducing the food into the cage. This food intake measured on $1{ }^{\text {st }} 24 \mathrm{hrs}$ fasting in deprivation paradigm was considered as control value.

On the subsequent day the rats were again kept fasting for $24 \mathrm{hrs}$. On the next day of fasting at 9am $2.5 \mathrm{mg} / \mathrm{kg}$ naloxone was injected intraperitoneally. The dose of Naloxone was chosen $2.5 \mathrm{mg} / \mathrm{kg}$ because naloxone $>1 \mathrm{mg} / \mathrm{kg}$ was found to suppress food intake ${ }^{11} .30$ mins after injection the food was weighed and introduced in cage. Then food intake was measured at $1 \mathrm{hr}, 2 \mathrm{hrs}$, $3 \mathrm{hrs}$ and $24 \mathrm{hrs}$.after introducing the food into the cage.

Food spillage on the cage floor was considered and weighed before and after each condition.

Then all male and all female rats were subjected to septal lesion.

Surgery: Rats were anesthetized using Sodium pentobarbitone with the dose of $35 \mathrm{mg} / \mathrm{kg}$ body weight, intraperitoneally and then given atropine $0.25 \mathrm{mg} / \mathrm{cc}$ to minimize respiratory discomfort.

Lesion maker: Instrument used was from Recorders and medicare systems, Chandigarh.

S.S. 44 square wave stimulator was used for making anodal lesions in predetermined sites. Microelectrodes were prepared by using 28/26 gauge stainless steel wire.

Operative Procedure for septal lesion: For precise location of electrodes, the stereotaxic apparatus was adjusted properly. It had an antero-posterior scale, a lateral scale and a vertical scale for proper 
placement of electrodes. The ear bars were adjusted equally. Then the electrode carrier with dummy electrode between the two ear bars was placed. The electrode was kept straight. The readings of AP bar and lateral scale are noted.

Lesioning Procedure: The anesthetized rat was fixed properly in the stereotaxic apparatus through ear bars. To achieve this first the ear clips were fixed into the ear of the animal. Then bars were inserted in clips and so adjusted their distance on either side was equal and the head was fixed. The incision of $1.5 \mathrm{~cm}$ length was made with razor blade on the skin of skull starting at the level behind the eyes. The membranous fascia covering the skull was cut away and skull surface was exposed, so that external landmark of sutures becomes visible. The Bregma was taken as reference point and with use of stereotaxic co-ordinates, the site to be implanted were marked with ink using a dummy electrode.

The hole was drilled at the marked points through the skull. The unipolar (anodal) electrode (28 gauge) varnished except at the tip was lowered stereotaxically in predetermined sites using Paxinos and Watson ${ }^{12}$. The other electrode (neutral) was fixed to the ear of animal. By using research stimulator S.S. 44, a DC anodal current at $15 \mathrm{~mA}$ intensity was passed through the electrodes for 20 sec. The lesions were made bilaterally.

\section{The co-ordinates for septal nuclei were as follows:}

$0.2 \mathrm{~mm}$ anterior to Bregma, $0.5 \mathrm{~mm}$ lateral on either side of sagittal suture, $5 \mathrm{~mm}$ lateral on either side of sagittal suture, $5 \mathrm{~mm}$ deep below the surface of skull bones.

After the procedure for septal lesion was over the electrodes were removed from the skull and skin was sutured and the site was cleaned with spirit. Nebasulf powder was applied and injection Benzathine penicillin 100,000 IU was given intramuscularly and animal was transferred to its cage.

At the end, septally lesioned rats were sacrificed by large dose of pentobarbitone sodium given intraperitoneally.

Then brain sections were taken and were subjected to histological examination by Prussian blue reaction. The sections were stained with 3\% potassium ferrocyanide solution for Prussian blue reaction at the site of lesion. Prussian blue reaction was indication of successful lesioning procedure. Then brain sections were counter stained with eosin and the extent of lesion was examined.

A period of 10 days was allowed for recovery from operative injury. The food intake was measured as was done before septal lesions. The effect of Naloxone injection on food intake after $24 \mathrm{hrs}$ fasting was measured in septally lesioned male and female rats.

\section{Statistical analysis:}

For data analysis all the values were expressed in terms of mean + standard error of Mean.

Differences between means were compared by applying paired' $t$ ' test. The effect was considered statistically significant if probability of chance was less than $0.05(\mathrm{p}<0.05)$.

The software used for statistics was Microsoft Excel 2003.

RESULTS: Table 1 shows basal food intake in male and female rats measured every $1 \mathrm{hr}$ for first $3 \mathrm{hrs}$ and then at $24 \mathrm{hrs}$. There is no significant difference in food intake of male rats and female rats. 


\begin{tabular}{|c|c|c|c|c|}
\hline Food intake in female rats (n=20) & 1hr & 2hrs & 3hrs & 24hrs \\
\hline Basal food intake (gms) & $0.8+0.24$ & $1.5+0.32$ & $2.6+0.45$ & $9.5+1.1$ \\
\hline Food intake in male rats (n=20) & & & & \\
\hline Basal food intake (gms) & $0.9+0.22$ & $1.8+0.16$ & $3.0+0.26$ & $11.5+0.9$ \\
\hline
\end{tabular}

Table 1: Basal food intake in male and female rats

Mean \pm SEM

The difference in food intake of male and female rats was not statistically significant

Table 2 shows effect of naloxone injection on food intake after 24 hrs. of food deprivation. There was significant hypophagia in both male and female rats at $1 \mathrm{hr}, 2 \mathrm{hrs}$ and $3 \mathrm{hrs}$. It shows that hypophagia was profound in initial hours of the day of the test after in deprivation paradigm. At 24 hrs. hypophagic effect had disappeared.

\begin{tabular}{|c|c|c|c|c|}
\hline After 24 hrs. fasting in female rats & $\mathbf{1 h r}$ & $\mathbf{2 h r s}$ & 3hrs & 24hrs \\
\hline Before naloxone injection & $1.9+0.40$ & $2.6+0.72$ & $4.3+0.83$ & $10.2+1.29$ \\
\hline After naloxone injection & $* 0.7+0.60$ & $* 1.2+0.18$ & $* 2.8+0.47$ & $13.0+0.66$ \\
\hline After 24 hrs. fasting in male rats & & & & \\
\hline Before naloxone injection & $2.0+0.27$ & $3.2+0.46$ & $5.3+0.80$ & $11.2+0.82$ \\
\hline After Naloxone injection & $* 1.0+0.24$ & $* 1.7+0.28$ & $* 3.0+0.59$ & $11.8+1.1$ \\
\hline
\end{tabular}

Table 2: Effect of Naloxone injection in deprivation paradigm in male and female rats.

Mean \pm SEM

$* \mathrm{P}<0.05$ Values are in grams.

Naloxone had induced hypophagia in male and female rats in deprivation paradigm.

Table 3 shows effect of septal lesion on food intake in male and female rats. In septally lesioned male and female rats there was no significant change in food intake after lesion was made. The food intake measured was in grams.

\begin{tabular}{|c|c|c|c|c|}
\hline & 1hr & 2hrs & 3hrs & 24hrs \\
\hline Basal food intake In female rats & & & & \\
\hline before septal lesion (gms) & $0.8+0.24$ & $1.5+0.32$ & $2.6+0.45$ & $9.5+1.1$ \\
\hline after septal lesion (gms) & $1.0+0.22$ & $1.8+0.43$ & $2.7+0.34$ & $10.1+0.81$ \\
\hline Basal food intake In male rats & & & & \\
\hline before septal lesion (gms) & $0.9+0.22$ & $1.8+0.16$ & $3.0+0.26$ & $11.5+0.9$ \\
\hline after septal lesion (gms) & $1.1+0.27$ & $2.3+0.38$ & $3.4+0.42$ & $12.3+0.68$ \\
\hline
\end{tabular}

Table 3: Effect of septal lesion on food intake in male and female rats

The change in food intake after septal lesion was not statistically significant. 
Table 4 shows effect of septal lesion on naloxone induced hypophagia in male and female rats. It was observed that injection of naloxone failed to induce hypophagia in food deprived rats $(24 \mathrm{hrs}$. food deprivation). Hypophagia was not seen even in initial hours after deprivation.

\begin{tabular}{|c|c|c|c|c|}
\hline After septal lesion in females & $\mathbf{1 h r}$ & $\mathbf{2 h r s}$ & 3hrs & 24hrs \\
\hline Before naloxone injection & $2.1+0.27$ & $3.3+0.38$ & $5.1+0.42$ & $11.3+0.68$ \\
\hline After Naloxone injection & $2.7+0.31$ & $3.5+0.43$ & $5.3+0.61$ & $14.0+0.63$ \\
\hline After septal lesion in males & & & & \\
\hline Before naloxone injection & $2.1+0.22$ & $3.1+0.43$ & $4.7+0.34$ & $10.8+0.81$ \\
\hline After Naloxone injection & $1.8+0.47$ & $2.5+0.65$ & $4.0+0.52$ & $12.9+1.11$ \\
\hline
\end{tabular}

Table 4: Effect of septal lesion on naloxone induced hypophagia in deprivation paradigm in male and female rats

In male and female rats, after septal lesions, naloxone failed to induce hypophagia.

\section{CONCLUSION:}

1) Naloxone induces hypophagia in deprived male and female rats in initial period.

2) Septal lesions do not change the food intake in male and female rats.

3) Septal lesions abolish hypophagic effect of naloxone.

DISCUSSION: In our study when we measured the basal food intake in male and female rats it was found that there was no significant difference. This could be explained on the basis of role of sex hormones in the regulation of food intake. Estrogen in females and testosterone in males decrease the food intake ${ }^{13,14}$.

In our study we found that naloxone, which is opioid receptor antagonist, induces hypophagia in food deprived male and female rats $(\mathrm{p}<0.05)$ as compared to controls (i.e. food intake in rats after $24 \mathrm{hrs}$ food deprivation without naloxone injection). These results concur with the earlier studies ${ }^{15}$. One of the main functions proposed for opioid peptides in the CNS is involvement in mediation of hunger component in the control of food intake. Changes in beta endorphin content of pituitary or hypothalamus has been demonstrated under condition designed to reflect changes in the state of hunger or satiety in rats. ${ }^{16}$ Several investigators have also reported that administration of beta endorphins in CNS increased food intake. ${ }^{17}$ Intake of food is selectively increased by mu-opioid agonist when injected into ventromedial striatum including nucleus accumbens. ${ }^{3}$ Other studies also show that agonists of mu, delta, kappa and ORL Opioid receptors increase food intake while opioid receptor blockade decreases food intake. ${ }^{18}$ Although morphine is not endogenous peptide it has been widely used in the study of involvement of opioid peptides in the control of food intake, thus understanding the role of opioid receptors in the feeding behavior. And therefore, it is not surprising that we found that naloxone, an opioid antagonist induced hypophagia in food deprived rats. The opioid receptor antagonist naltrexone was recently shown in clinical trials to lower body weight which is being thought to be effective in treatment of obesity. ${ }^{19,20}$

Coexisting finding in our study was that the hypophagia was observed only in initial period of the day after naloxone injection. This can be attributed to the fact that naloxone has shorter half-life 
of $1 \mathrm{hr}$ and the duration of naloxone action varies from 30min to $4 \mathrm{hrs} .{ }^{21}$ Therefore hypophagia was not observed at $24 \mathrm{hrs}$.

It has been suggested that obesity is correlated with increased levels of opioid peptides.

Increased sensitivity to opioid antagonist, in models of obesity has been interpreted to support this concept. Morgules and associates ${ }^{22}$ showed that genetically obese rats and mice, in addition to having increased beta endorphin concentration in pituitary, were responsive to the effects of naloxone on food intake in obese than in lean rats, thus suggesting that opiates may play causal role in the development of obesity.

In our study we were particularly interested in investigating the role of septal projections to hypothalamus in regulation of food intake. Septal lesions did not alter the food intake in both male and female rats. The reports from some of the other studies also show that rats after lesion in septal area food intake was not changed significantly. ${ }^{23}$ Another study shows that there was no significant alteration in food intake after lesion of nucleus septal medialis. ${ }^{24}$

Though septum is a key component of limbic system and has several neural connections with hypothalamus various brain areas are involved in the central control over the alimentary mechanisms of food intake. Most important are the hypothalamus, amygdaloid complex and midbrain. Much of the support for the hypothalamic role in food and water intake regulation derives from the observation that lesions in dorsolateral hypothalamus produce aphasia and adipsia, whereas, electrical stimulation of this region elicits ingestive behavior. However, the area is traversed by numerous fiber systems, ${ }^{23}$ including components of median forebrain bundle, afferent and efferent connections of striatum, amygdofugal and septal projections and many of sensory pathways. When septal projections to hypothalamus are lesioned other connections are still intact. This may be the reason for having no alteration in food intake after septal lesion.

In our study we found that naloxone failed to induce hypophagia in food deprivation paradigms in septally lesioned male and female rats. As mentioned earlier in this discussion there is larger population of mu-opioid receptors in and around septum. The results therefore suggest that population of opioid receptors in septal region may be involved in naloxone induced hypophagia. But still how do these Opioid receptors and septal lesions interact in regulation of food intake needs to be further investigated.

\section{REFERENCES:}

1. World Health Organisation. Genomics and World Health, Report of the Advisory Committee on Health Research: Summary. 2002.

2. Hetherington AW, Ranson SW. The relation of various hypothalamic lesions to adiposity in the rats. J. Comp. Neur. 1942; 76: 475-499.

3. Anand BK, Brobek GR. Localisation of feeding centre in hypothalamus. Proceedings of the society for experimental biology and Medicine 1951, 77:323-24.

4. Anand BK, Dua S. Feeding responses induced by electrical stimulations of the hypothalamus in the cat. Indian journal of medical research 1955; 43: 113-22.

5. Cupples WA. Integrating the regulation of food intake. Am J Physiol Regulatory Integrative Comp Physiol 2002; 283: R356-R357.

6. Swanson LW, Cowen WM. The connections of septal region in the rat. J Comp Neurol. 1979; 186: 621-656. 


\section{ORIGINAL ARTICLE}

7. Leibowitz SF. Perspectives in behavioural medicine: eating, regulation and discontrol (Weiner $\mathrm{H}$ and Baum A eds.) 1988, PP: 113-136.

8. Temple DL, Leibiwitz SF. PVN implants: Effects on feeding pattern and micronutrient selection. Brain Res Bull 1989; 23: 553-560.

9. Cooper SJ, Sanger DJ. Endorphinergic mechanisms in food, salt and water intake: an overview. Appetite 1984; 5: 1-6.

10. Gold MS, Sternbach HA. Endorphins in obesity and in the regulation of appetite and weight. Intra. Psychiatry 1984; 2: 203-207.

11. Tallett AJ, Blundell JE, Rodgers RJ Behaviourally-selective hypophagic effects of naloxone in non-deprived male rats presented with palatable food. Behav Brain Res. 2008 187(2):417-427.

12. Paxions G, Watson C. The rat brain in stereotaxic co-ordinates, 2nd ed, Sydney, Australia, 1986: Academic Press.

13. Blaustein JD, Wade GN. Ovarian influences on meal patterns of female rats. Physiol Behav.1976; 17: 201-208.

14. DuPont, A, Barden N, Cusan C. P-endorphin and met-enkephalin: Their distribution, modulation by estrogens and haloperidol, and role in neuroendocrine control. Fed Proc. 1980; 39: 2544.

15. Berthoud HR. Multiple neural systems controlling food intake and body weight. Neuroscience and Biobehavioral Reviews 2002; 26:393-428.

16. Le Merrer J, Caqniard B, Cazala P. Modulation of anxiety by mu Opioid receptors of the lateral septal region in mice. Pharmacol Biochem Behav 2006; 83: 465-479.

17. Jones JG, Ritcher JA. The site of action of naloxone in suppressing food and water intake in rats. Life science 1981; 18: 2055-2064.

18. Gambert SR, Garthwaite JL, Pontzer CH, Hagen TC. Endogenous opiates and fasting. Science 1981; 213: 1282-1283.

19. Marczak ED, Jinsmaa Y, Myers PH, et al. Orally administered H-Dmt-Tic-Lys-NH-CH2-Ph (MZ-2), a potent mu/delta-opioid receptor antagonist, regulates obese-related factors in mice. Eur J Pharmacol. 2009; 616(1-3):115-121.

20. Greenway FL, Fujioka K, Plodkowski RA. 2010 Effect of naltrexone plus bupropion on weight loss in overweight and obese adults (COR-I): a multicentre, randomised, double-blind, placebocontrolled, phase 3 trial. Lancet 2010; 376:595-605.

21. Helms RA, Quan DJ (eds). Textbook of Therapeutics: Drug and Disease Management. 8th ed. Philadelphia: Lippincott Williams St Wilkins; 2006. p 82.

22. Marguls BI, Maisset B, Lewis MJ, Shibuia H, Pert CB. Beta endorphin is associated with overeating in genetically obese mice and rats. Science 1978; 202: 988-991.

23. Lorens AS, Kondo CY. Effect of septal lesion on food and water intake. Physiology and behaviour 1969; 4: 729-732.

24. Dev S, Pal GK, Pal P. Effect of lesion of nucleus septal medialis on energy homeostasis in Wistar rats. Indian J Physiol Pharmacol 2012; 56:314-321.

25. Glass MJ, Billinton CJ, Levin AS. Opioid and food intake: distribution of neural pathways. Neuropeptides 1999; 33: 360-368. 


\section{ORIGINAL ARTICLE}

\section{AUTHORS:}

1. A.R. Gargate

2. R.V. Gargate

\section{PARTICULARS OF CONTRIBUTORS:}

1. Professor, Department of Physiology, Institute of Medical Sciences and Research, Mayani.

2. Assistant Professor, Department of Paediatrics, Institute of Medical Sciences and Research, Mayani.

\section{NAME ADDRESS EMAIL ID OF THE} CORRESPONDING AUTHOR:

Dr. A. R. Gargate,

Department of Physiology,

Institute of Medical Sciences and Research, Mayani.

E-mail: ashwinigargate@yahoo.in

Date of Submission: 15/01/2014.

Date of Peer Review: 16/01/2014.

Date of Acceptance: 04/02/2014.

Date of Publishing: 12/02/2014. 